\title{
Computational pharmacokinetic analysis on some newly designed 2-anilinopyrimidine derivative compounds as anti-triple- negative breast cancer drug compounds
}

\author{
Hadiza Lawal Abdulrahman*, Adamu Uzairu and Sani Uba
}

\begin{abstract}
Introduction: Worldwide, cancer of the breast is the most commonly diagnosed disease and the second leading cause of cancer-related mortality amongst women yearly (Miller et al., 2016). Computer-aided drug discovery (CADD) is a fundamental shortcut in drug discovery arena. CADD tools ascertain key molecule for testing, predicting the effectiveness, the possible side effect, and also assist in upgrading drug-likeliness of drug molecules (Leelananda and Lindert, 2016). The propose of carrying out this research is to design new 2-anilinopyrimidine derivative compounds based on the interaction of the derivative compounds (ligand) and thyroid hormone receptor (TR $\beta 1$ ), and also analyze their pharmacokinetic properties as drug compounds that would be used by the pharmaceuticals against triple-negative breast cancer (MDA-MB-468 cell line).

Results: Three compounds $(12,17$, and 18$)$ had the highest docking score ranging from -7.3 to $-7.4 \mathrm{kcal} / \mathrm{mol}$. This showed that the compounds (ligands) bind tightly with the active site of the thyroid hormone receptor (TR 31 ). Based on their tight interactions with the receptor, the compounds were chosen as lead compounds in the design of fourteen new compounds by incorporating some fragments found to bind intensely with the active site of the thyroid hormone receptor (TR 31 ). All the newly designed compounds passed the pharmacokinetic analysis (adsorption, distribution, metabolism, excretion, and other physicochemical test) passed the drug-likeness test, and they also adhered to the Lipinski rule of five.
\end{abstract}

Conclusions: New derivative compounds of 2-anilinopyrimidine against MDA-MB-468 cell line were designed based on the information obtained from the molecular docking studies. Furthermore, the pharmacokinetics analysis (adsorption, distribution, metabolism, excretion (ADME) and other physicochemical properties) carried out on the newly designed compounds showed this compounds can be made into oral drugs for patients with triple-negative breast cancer (MBA-MD-468 cell line) as they serve as most promising inhibitors against thyroid hormone receptor (TRß1).

Keywords: Molecular docking studies, 2-anilinopyrimidine, MDA-MB-468 cell line, Thyroid hormone receptor (TRß1), Structure-based design, Pharmacokinetic analysis

* Correspondence: azeezalawal@gmail.com

Department of Chemistry, Ahmadu Bello University, P.M.B. 1044, Zaria,

Nigeria

(c) The Author(s). 2020 Open Access This article is licensed under a Creative Commons Attribution 4.0 International License, which permits use, sharing, adaptation, distribution and reproduction in any medium or format, as long as you give appropriate credit to the original author(s) and the source, provide a link to the Creative Commons licence, and indicate if changes were made. The images or other third party material in this article are included in the article's Creative Commons licence, unless indicated otherwise in a credit line to the material. If material is not included in the article's Creative Commons licence and your intended use is not permitted by statutory regulation or exceeds the permitted use, you will need to obtain permission directly from the copyright holder. To view a copy of this licence, visit http://creativecommons.org/licenses/by/4.0/. 


\section{Introduction}

Mammary tumor is a tumor initiating from the mammary tissues, frequently from the inside lining of milk ducts or the lobules that supply the ducts with milk (Sharma et al., 2010). Worldwide, breast cancer is the commonly identified disease and the second cancer-related mortality amongst the women folk yearly (Miller et al., 2016). Breast cancer can be categorized into invasive and non-invasive types; non-invasive breast cancer is a cancer type that does not stretch out of the lobule or ducts where it situated (estrogen receptor (ER)-/progesterone receptor (PR)- positive type $(\sim 80 \%)$ and human epidermal growth factor receptor 2 (HER $2+)$ positive type $(\sim 5 \%))$ while the invasive breast cancer type extends into the neighboring tissues outside the milk duct (triple-negative type (10-15\%)) (Akram et al., 2017).

The traditional process of discovering and developing drugs is very costly and consumes a lot of time. Traditional methods of drug findings depend on a step by step synthesis and filtering of many molecules to find a lead molecule (Kapetanovic, 2008).

Computer-aided drug discovery (CADD) and design confirms the best potential compound; it reduces the cost related to discovering a drug, and it also reduces the time taken for a drug to get to the consumer market. It is a fundamental shortcut in the drug discovery arena. CADD tools ascertain potential molecule to be tested, predicting the efficacy, the possible side effect, and also aid to upgrade the drug-likeliness of drug molecules (Leelananda and Lindert, 2016). The frequently used CADD techniques are the structure-based drug discovery (SBDD). The propose is to obtain ligands with specific electrostatic and physicochemical properties to gain higher docking score. In SBDD, the therapeutics are designed based on the information of the crystalized macromolecule also known as a receptor (Ferreira et al., 2015).

There are lots of drug compounds that do not pass the drug-likeness analysis. Efficiency and safety of the drug to the human system are the main cause of drug failure, which indicates the absorption, distribution, metabolism, excretion, and toxicity (ADMET) properties of molecules plays an essential role in every stage of drug discovery and development. Therefore, it is compulsory to find potent molecules with better ADMET properties (Guan et al., 2019).

Recently, thirty derivative compounds of 2anilinopyrimidine were reported by Jo et al., 2019 as inhibitors against MDA-MB-468 cell line. This study is aimed to design new derivative compounds based on the interaction of the derivative compounds (ligand) and thyroid hormone receptor (TR $\beta 1$ ), and also analyze their pharmacokinetic properties as drug compounds that would be used by the pharmaceuticals against triple-negative breast cancer (MDA-MB-468 cell line).

\section{Methods}

\section{Data collection}

Thirty (30) novel derivative compounds of 2anilinopyrimidine with their inhibitory concentration $\left(\mathrm{IC}_{50}\right)$, against triple breast cancer (MDA-MB-468) cell line, were acquired from (Jo et al., 2019) reports. Figure 1 shows the template of the 2-anilinopyrimidine derivatives compounds while Table 1 shows the structures that was attached to the Fig. 1.

\section{Molecular docking studies}

2-Anilinopyrimidine derivative compounds (Table 1) underwent molecular docking studies with the thyroid hormone receptor (TR $\beta 1)$. The crystal structure was obtained from RCSB PDB (https://www.rcsb.org) with the ID, 1Y0X. The docking scores of the ligand-receptor complex were calculated with Autodock Vina of the Pyrx software (Abdulfatai et al., 2018; Abdullahi et al., 2019). Visualizer of Discovery Studio was used to understand the ligand-protein target interactions.

\section{Computational pharmacokinetics (drug-likeness)}

The SwissADME, a free web tool used in evaluating the pharmacokinetics, drug-likeness (physicochemical and ADME properties) and medicinal chemistry friendliness of small molecules (Diana et al., 2017) was used in testing the drug-likeness of the newly designed compounds. Furthermore, some physicochemical properties and positive controls of the designed compounds were checked using the on-line tool for their familiarity with Lipinski's

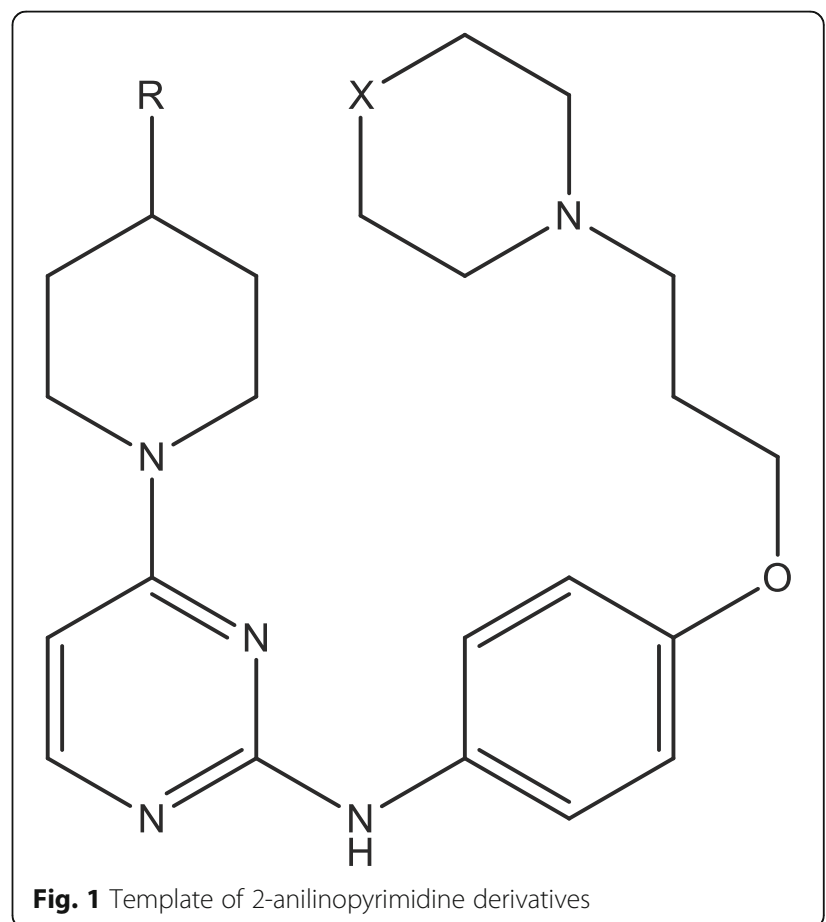


Table 1 : 2-anilimopyrimidine derivatives compounds

\begin{tabular}{|c|c|c|}
\hline Structure & $\mathbf{R}$ & $\mathbf{X}$ \\
\hline 1 & $\mathrm{H}$ & $\mathrm{O}$ \\
\hline 2 & - & o \\
\hline 3 & - & $\mathrm{S}$ \\
\hline 4 & - & $\mathrm{CH}_{2}$ \\
\hline 5 & - & o \\
\hline 6 & - & $\mathrm{S}$ \\
\hline 7 & - & $\mathrm{CH}_{2}$ \\
\hline 8 & - & o \\
\hline 9 & - & $\mathrm{S}$ \\
\hline 10 & - & $\mathrm{CH}_{2}$ \\
\hline 11 & $\mathrm{H}$ & $\mathrm{O}$ \\
\hline 12 & $\mathrm{H}$ & $\mathrm{CH}_{2}$ \\
\hline 13 & $\mathrm{Me}$ & $\mathrm{O}$ \\
\hline 14 & $\mathrm{Me}$ & $\mathrm{S}$ \\
\hline 15 & $\mathrm{Cl}$ & $\mathrm{CH}_{2}$ \\
\hline 16 & $\mathrm{Cl}$ & O \\
\hline 17 & $\mathrm{Cl}$ & $\mathrm{S}$ \\
\hline 18 & $\mathrm{Cl}$ & $\mathrm{CH}_{2}$ \\
\hline 19 & - & o \\
\hline 20 & - & $\mathrm{S}$ \\
\hline 21 & - & $\mathrm{CH}_{2}$ \\
\hline 22 & - & o \\
\hline 23 & 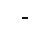 & $\mathrm{S}$ \\
\hline 24 & - & $\mathrm{CH}_{2}$ \\
\hline 25 & & - \\
\hline 26 & & - \\
\hline 27 & & - \\
\hline 28 & & - \\
\hline 29 & & - \\
\hline 30 & & - \\
\hline
\end{tabular}


Table 2 Binding affinities, interaction types, bond types, and bond distances between some compounds and the receptor

\begin{tabular}{|c|c|c|c|c|c|}
\hline Complex & Binding affinity $(\mathrm{kcal} / \mathrm{mol})$ & Amino acid & Bond type & Interaction & Distance $\left(A^{0}\right)$ \\
\hline \multirow[t]{7}{*}{30} & -5.9 & LEU360 & Hydrogen bond & Conventional hydrogen bond & 2.19527 \\
\hline & & LEU360 & Hydrogen bond & Conventional hydrogen bond & 2.08848 \\
\hline & & VAL319 & Hydrogen bond & Carbon hydrogen bond & 3.03818 \\
\hline & & SER361 & Hydrogen bond & Pi-donor hydrogen bond & 3.21568 \\
\hline & & VAL319 & Hydrophobic & Alkyl & 5.40031 \\
\hline & & TRP239 & Hydrophobic & Pi-alkyl & 5.30319 \\
\hline & & TRP239 & Hydrophobic & Pi-alkyl & 4.57531 \\
\hline \multirow[t]{8}{*}{12} & -7.2 & GLY432 & Hydrogen bond & Conventional hydrogen bond & 2.96575 \\
\hline & & GLY432 & Hydrophobic & Amide-Pi stacked & 3.88004 \\
\hline & & |LE303 & Hydrophobic & Alkyl & 5.23513 \\
\hline & & LYS306 & Hydrophobic & Alkyl & 4.84663 \\
\hline & & ARG383 & Hydrophobic & Alkyl & 5.07109 \\
\hline & & PRO384 & Hydrophobic & Alkyl & 5.29712 \\
\hline & & ALA433 & Hydrophobic & Pi-alkyl & 4.14051 \\
\hline & & ALA436 & Hydrophobic & Pi-alkyl & 5.48801 \\
\hline \multirow[t]{11}{*}{18} & -7.3 & GLU311 & Hydrogen bond & Conventional hydrogen bond & 2.10982 \\
\hline & & ARG429 & Hydrogen bond & Conventional hydrogen bond & 2.68544 \\
\hline & & GLY307 & Hydrogen bond & Conventional hydrogen bond & 2.97669 \\
\hline & & GLU311 & Hydrogen bond & Conventional hydrogen bond & 2.85424 \\
\hline & & VAL458 & Hydrogen bond & Carbon hydrogen bond & 3.34145 \\
\hline & & ILE303 & Hydrophobic & Alkyl & 5.28774 \\
\hline & & LYS306 & Hydrophobic & Alkyl & 4.9622 \\
\hline & & ARG383 & Hydrophobic & Alkyl & 5.40494 \\
\hline & & PRO384 & Hydrophobic & Alkyl & 4.84454 \\
\hline & & PRO384 & Hydrophobic & Alkyl & 5.15235 \\
\hline & & ALA436 & Hydrophobic & Pi-alkyl & 4.91503 \\
\hline \multirow[t]{10}{*}{15} & -7.4 & GLU311 & Hydrogen bond & Conventional hydrogen bond & 2.15506 \\
\hline & & ARG429 & Hydrogen bond & Conventional hydrogen bond & 2.57929 \\
\hline & & GLU311 & Hydrogen bond & Conventional hydrogen bond & 2.76094 \\
\hline & & VAL458 & Hydrogen bond & Carbon hydrogen bond & 3.37649 \\
\hline & & ILE303 & Hydrophobic & Alkyl & 5.43788 \\
\hline & & LYS306 & Hydrophobic & Alkyl & 5.04683 \\
\hline & & ARG383 & Hydrophobic & Alkyl & 5.3858 \\
\hline & & PRO384 & Hydrophobic & Alkyl & 5.11068 \\
\hline & & PRO384 & Hydrophobic & Alkyl & 4.78448 \\
\hline & & PRO384 & Hydrophobic & Alkyl & 4.75312 \\
\hline \multirow[t]{11}{*}{17} & -7.4 & GLY432 & Conventional hydrogen bond & Alkyl & 2.88081 \\
\hline & & GLY432 & Carbon hydrogen bond & & 3.57426 \\
\hline & & GLY432 & Hydrophobic & Alkyl & 3.93288 \\
\hline & & |LE303 & Hydrophobic & Alkyl & 5.3903 \\
\hline & & LYS306 & Hydrophobic & Alkyl & 5.01206 \\
\hline & & ARG383 & Hydrophobic & Alkyl & 4.96917 \\
\hline & & PRO384 & Hydrophobic & Alkyl & 5.19799 \\
\hline & & ARG429 & Hydrophobic & Alkyl & 5.05991 \\
\hline & & MET430 & Hydrophobic & Alkyl & 5.44203 \\
\hline & & ALA433 & Hydrophobic & Pi-alkyl & 4.23025 \\
\hline & & ALA436 & Hydrophobic & Pi-alkyl & 5.44549 \\
\hline
\end{tabular}




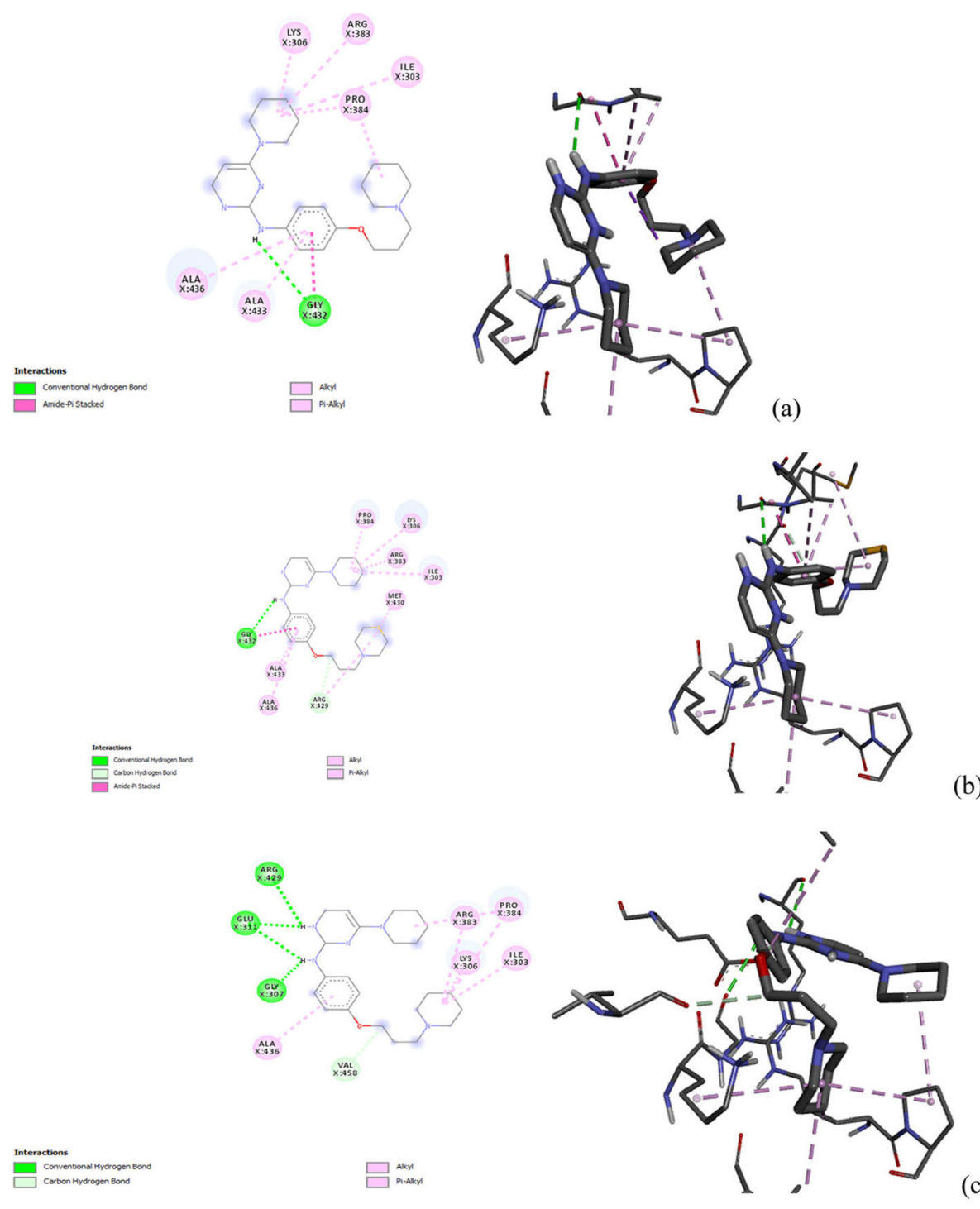

(b)

(c)

Fig. $22 D$ and 3D format of complex a 12, b 17, and c 18

rule of five (Hou et al., 2019). Lipinski and co-workers proposed the "Rule of Five" in 1997, which was the geniuneand most famous rule-based filter for drug-likeness of a molecule, distinguishing whether a molecule can be orally absorbed well or not, following the criteria: molecular weight $(\mathrm{MW}) \leq 500$, octanol/water partition coefficient $(\mathrm{A} \log \mathrm{P}) \leq 5$, number of hydrogen bond donors $(\mathrm{HBDs}) \leq 5$, and number of hydrogen bond acceptors (HBAs) $\leq 10.6$. According to the rule of five, a compound fails to be active orally when it breaks two or more rules out of the Lipinski's rule of five (Guan et al., 2019).

\section{Results}

Table 2 shows a summary of the docking scores, the various interactions (hydrogen and hydrophobic), and their bond lengths that occurred between some selected 2-anilinopyrimidine derivatives compounds (ligand) that had the highest docking scores and the amino acid residues of the thyroid hormone (TR $\beta 1$ ) receptor. The docking scores of the ligand-receptor to form a complex were calculated with Autodock Vina of the Pyrx software and visualized using the Discovery Studio Software. Figure 2 showed the ligand-receptor interaction of complexes 12,17 , and 18 in both $2 \mathrm{D}$ and $3 \mathrm{D}$ format.

\section{Structure-based design}

Using the results obtained from the molecular docking studies, compounds 12,17 , and 18 had the highest docking scores and were used in the design of fourteen (14) new 2-anilinopyrimidine derivative compounds using the structure-based design technique, based on the information obtained from the binding site of the crystalized 
macromolecule known as a receptor. The newly designed compounds are shown in Table 3.

\section{Computational pharmacokinetic analysis (physicochemical and ADME properties) of the newly designed 2-anilinopyrimidine compounds}

All the newly designed compounds were tested for their drug-likeliness "drug-likeliness, assess quantitatively the chance for a molecule to become an oral drug with respect to bioavailability." SwissADME on-line software was used to ascertain the drug-likeness of the designed compounds before the can proceed to pre-clinical trials. Table 4 shows the pharmacokinetic results of the designed compounds. Figure 3 shows the bioavailability radar of molecules 3,12 , and 14. The bioavailability radar gives a main scan at the drug-likeness of a compound (Diana et al., 2017).

\section{Discussion}

\section{Molecular docking studies}

Molecular docking on compounds of 2-anilinopyrimidine with the protein target, thyroid hormone receptor (TR $\beta 1)$, was performed. Amongst all the derivatives, compounds $12,15,17,18$, and 30 had high docking scores ranging from -5.9 to $-7.4 \mathrm{kcal} / \mathrm{mol}$. The visual examination of the docked complexes was carried out by a careful examination of hydrogen bond interaction, hydrogen bond length, and hydrophobic interaction.

Compound 12 exhibited hydrogen bonding with GLY432 $\left(2.96575 \mathrm{~A}^{0}\right)$ amino acid residue. Furthermore, the piorbital containing delocalized electrons in the benzene ring interact with the alkyl groups of ILE303 $\left(5.23513 \mathrm{~A}^{0}\right)$, LYS306 $\left(4.84663 \mathrm{~A}^{0}\right), \quad$ ARG383 $\left(5.07109 \mathrm{~A}^{0}\right), \quad$ PRO384 $\left(5.29712 \mathrm{~A}^{0}\right)$, ALA433 (4.14051 $\left.\mathrm{A}^{0}\right)$, and ALA436 (5.48801 $\left.\mathrm{A}^{0}\right)$ amino acid residue to form hydrophobic bond.

Compound 18 also showed the same hydrogen bonding with amino acid residues of GLU311 $\left(2.10982 \mathrm{~A}^{0}\right)$, ARG439 (2.68544 A $\left.{ }^{0}\right)$, GLY307 (2.97669 A $\left.{ }^{0}\right)$, GLU311 $\left(2.85424 \mathrm{~A}^{0}\right)$, and carbon hydrogen bonding with VAL458 $\left(3.34145 \mathrm{~A}^{0}\right)$. Also, the compound formed hydrophobic bond with the amino acids of ILE303 $\left(5.28774 \mathrm{~A}^{0}\right), \operatorname{LYS} 306\left(4.9622 \mathrm{~A}^{0}\right)$, ARG383 (5.40494 $\left.\mathrm{A}^{0}\right), \quad$ PRO384 $\left(4.84454 \mathrm{~A}^{0}\right.$ and $\left.5.15235 \mathrm{~A}^{0}\right)$, and ALA436 (4.91503 $\left.\mathrm{A}^{0}\right)$.

Compound 17 also showed two hydrogen bonding with GLY4432 (2.88081 and $\left.3.57426 \mathrm{~A}^{0}\right)$ of the active site of the receptor. The derivative also formed hydrophobic bonds (3.93288, 5.3903, 5.01206, 4.96917, 5.19799, 5.05991, 5.44203, 4.23025, and 5.44549 $\mathrm{A}^{0}$ ) with amino acids of GLY432, ILE303, LYS306, ARG383, PRO384, ARG429, MET430, ALA433, and ALA436 of the protein target. The carbonyl of the compound attached to 3-methylenedihydrofuran-2(3H)-one act as a hydrogen acceptor to form one hydrogen bond with LSY134.
Table 3 Newly designed 2-anilinopyrimidine compounds against MBA-MB-468 cell line

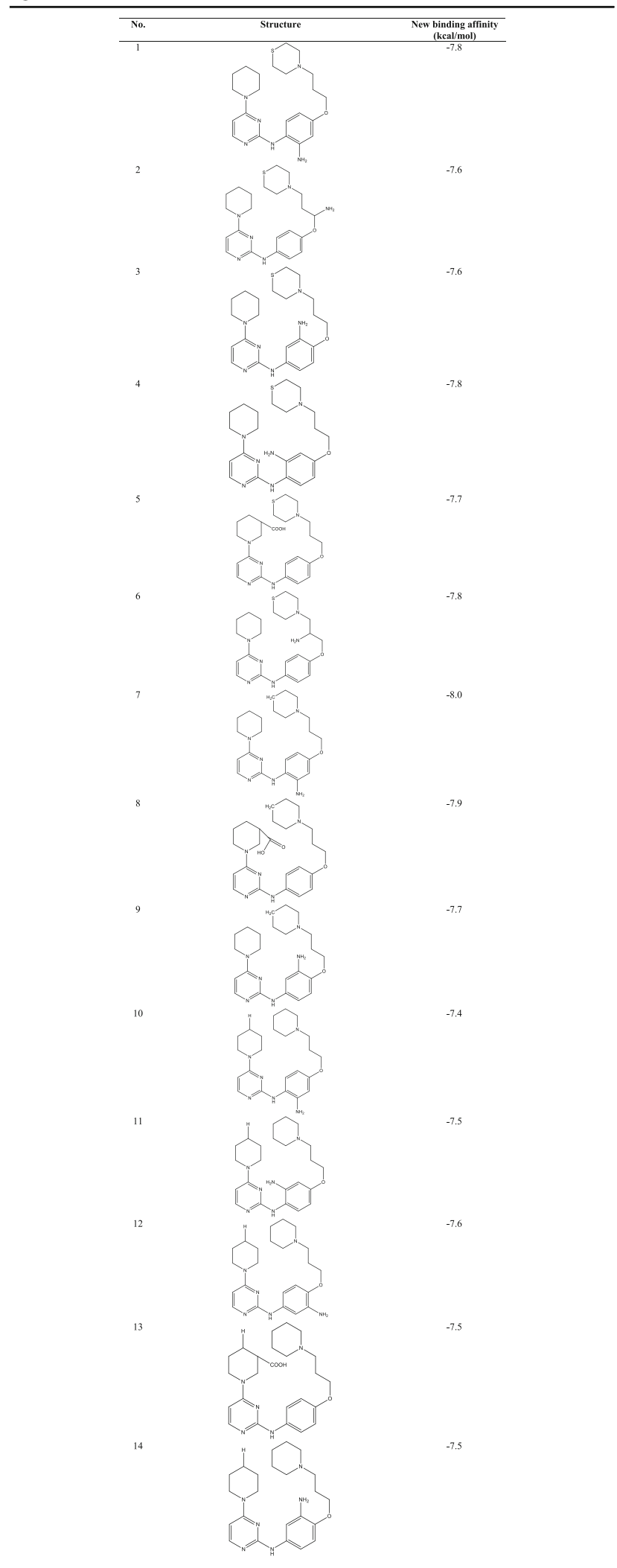


Table 4 Pharmacokinetic properties of the newly designed 2-anilinopyrimidine compounds against MDA-MB-468 cell line

\begin{tabular}{llllllllllll}
\hline No. & MW $(\mathrm{g} / \mathrm{mol})$ & $\mathrm{nHA}$ & $\mathrm{nRA}$ & $\mathrm{HBA}$ & $\mathrm{HBD}$ & $\mathrm{MR}$ & TPSA & iLOGP & BBB & PAINS & Brenk \\
\hline $17 \mathrm{a}$ & 428.59 & 12 & 8 & 4 & 2 & 133.05 & 104.84 & 3.77 & No & 0 & 1 \\
$17 \mathrm{~b}$ & 428.59 & 12 & 8 & 5 & 2 & 131.35 & 104.84 & 3.67 & No & 0 & 1 \\
$17 \mathrm{c}$ & 425.59 & 12 & 8 & 4 & 2 & 133.05 & 104.84 & 3.66 & No & 0 & 1 \\
$17 \mathrm{~d}$ & 428.59 & 12 & 8 & 4 & 2 & 133.05 & 104.84 & 3.77 & No & 0 & 1 \\
$17 \mathrm{f}$ & 457.59 & 12 & 9 & 6 & 2 & 135.23 & 116.12 & 3.53 & No & 0 & 1 \\
$18 \mathrm{a}$ & 410.56 & 12 & 8 & 4 & 2 & 130.54 & 79.54 & 3.87 & No & 0 & 1 \\
$18 \mathrm{~b}$ & 439.55 & 12 & 9 & 6 & 2 & 132.44 & 90.82 & 3.67 & No & 0 & 0 \\
$18 \mathrm{c}$ & 410.56 & 12 & 8 & 4 & 2 & 130.27 & 79.54 & 3.97 & No & 0 \\
$17 \mathrm{~h}$ & 428.59 & 12 & 8 & 5 & 2 & 131.35 & 104.84 & 3.87 & No & 0 \\
$12 \mathrm{a}$ & 410.56 & 12 & 8 & 4 & 2 & 130.27 & 79.54 & 3.87 & No & 0 \\
$12 \mathrm{~b}$ & 410.56 & 12 & 8 & 4 & 2 & 130.27 & 79.54 & 3.87 & No & 0 \\
$12 \mathrm{c}$ & 410.56 & 12 & 8 & 4 & 2 & 130.27 & 79.54 & 3.97 & No & 0 \\
$12 \mathrm{~d}$ & 439.55 & 12 & 9 & 6 & 2 & 132.44 & 90.82 & 3.67 & No & 0 \\
$12 \mathrm{e}$ & 410.56 & 12 & 8 & 4 & 2 & 130.27 & 79.54 & 3.97 & No & 0 \\
\hline
\end{tabular}

$M W$ molecular weight $(<500 \mathrm{mg} / \mathrm{mol}), n A H$ number of aromatic heavy atoms, $n R B$ number of rotatable bonds, HBA hydrogen bond acceptors, $H B D$ hydrogen bond donors, MR molecular refractivity, TPSA topological polar surface area, BBB blood-brain barrier

All the compounds showed the same hydrogen bond and hydrophobic bond interactions with the amino acid residues of the receptor at different distances. The binding affinity of the ligands was higher than that of the standard drug Gefitinib (- $5.3 \mathrm{kcal} / \mathrm{mol})$. From the compounds interaction with the receptor, it proves the ability of the compounds to inhibit thyroid hormone (TR $\beta 1)$ receptor.

\section{Structure-based design}

Compounds 12, 17, and 18 were chosen as lead compounds because they had the highest docking scores. The ligand-receptor interactions as shown in Fig. 2 indicate the points of interactions between the compounds and the amino acid residues of the receptor. Therefore, modifications were made on the lead compounds by incorporating some fragments found to bind intensely with the active-site of thyroid hormone (TR $\beta 1$ ) based on the mode of interactions that occurred between the ligand and receptor as shown in Table 3.

\section{Pharmacokinetics analysis (physicochemical and ADME properties) of the newly designed 2-anilinopyrimidine compounds}

All the fourteen (14) designed compounds passed the drug-likeliness test as shown in Table 4; they also passed the Lipinski rule of five, a criteria used as a guide in drug design (the molecules that adhere to three rules out of the four rules are said to obey to Lipinski rule (Diana et al., 2017)). The gastrointestinal absorption of all the new compounds was found to be high, making the compounds a breakthrough in finding the cure for triplenegative breast cancer.

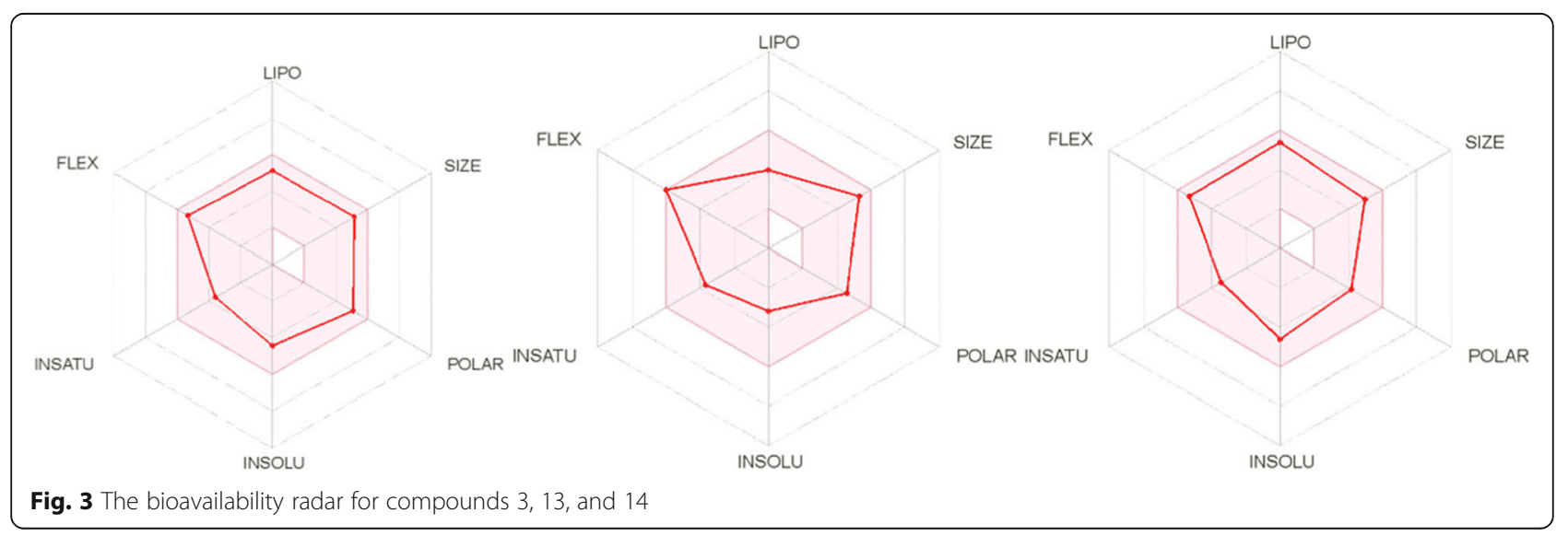




\section{Conclusion}

New derivative compounds of 2-anilinopyrimidine against MDA-MB-468 cell line were designed based on the information obtained from the molecular docking studies. Molecular docking studies were used in understanding the interaction in details between the compounds (ligands) and thyroid hormone receptor (TR $\beta 1$ ). From the docking score, compounds 12, 17, and 18 were used as lead compounds in designing twelve new derivative compounds due to their high docking scores. Modifications were made on the lead compounds by incorporating some fragments found to bind intensely with the active site of the receptor (TR $\beta 1)$.

Furthermore, the pharmacokinetics analysis (ADME and other physicochemical properties) carried out on the newly designed compounds showed this compounds can be made into oral drugs for patients with triplenegative mammary tumor (MBA-MD-468 cell line) because they passed the drug-likeness test, and they also obey the Lipinski rule of five. This gives a great development to rescuing the female race by developing more effective anti-breast cancer drug to concur this deadly disease.

\begin{abstract}
Abbreviations
$\mathrm{IC}_{50}$ : Inhibitory concentration; TR $\beta 1$ : Thyroid hormone receptor; ADMET: Adsorption, distribution, metabolism, excretion, and toxicity; MW: Molecular weight (<500mg/mol); nAH: Number of aromatic heavy atoms; nRB: Number of rotatable bonds; HBA: Hydrogen bond acceptors; HBD: Hydrogen bond donors; MR: Molecular refractivity; TPSA: Topological polar surface area; BBB: Blood-brain barrier
\end{abstract}

\section{Acknowledgements}

Authors acknowledge the technical effort of physical chemistry department, Ahmadu Bello University Zaria for their immense advice and various contribution toward the successful completion of the research.

\section{Authors' contributions}

HAL gathered the data sets and analyzed it computationally in accordance with the methodology to get a model of high performance and was a major contributor in drafting the manuscript. AU carried out statistical analysis on the model to ensure its stability and also participated in the write up, and SU re-edited the work and ensured it conforms with the manuscript's guide. All the authors read and approved the final manuscript.

\section{Funding}

This research did not receive any specific grant from funding agencies in the public, commercial, or not-for-profit sectors.

\section{Availability of data and materials}

Not applicable

Ethics approval and consent to participate

Not applicable

\section{Consent for publication}

Not applicable

\section{Competing interests}

The authors declare no conflict of interest.
Received: 1 February 2020 Accepted: 14 April 2020

Published online: 28 April 2020

\section{References}

Abdulfatai U, Uzairu A, Uba S (2018) Molecular docking and quantitative structure-activity relationship study of anticonvulsant activity of aminobenzothiazole derivatives. Beni Suef Univ J Basic App Sci 7(2):204-214

Abdullahi M, Uzairu A, Shallangwa GA, Mamza P, Arthur DE, Ibrahim MT (2019) In-silico modelling studies on some C14-urea-tetrandrine derivatives as potent anti-cancer agents against prostate (PC3) cell line. Journal of King Saud University-Science

Akram M, lqbal M, Daniyal M, Khan AU (2017) Awareness and current knowledge of breast cancer. Biol Res 50(1):33

Daina A, Michielin O, Zoete V (2017) SwissADME: a free web tool to evaluate pharmacokinetics, drug-likeness and medicinal chemistry friendliness of small molecules. Sci Rep 7:42717

Ferreira L, dos Santos R, Oliva G, Andricopulo A (2015) Molecular docking and structure-based drug design strategies. Molecules 20(7):13384-13421

Guan L, Yang H, Cai Y, Sun L, Di P, Li W et al (2019) ADMET-score-a comprehensive scoring function for evaluation of chemical drug-likeness. Med Chem Comm 10(1):148-157

Hou Y, Zhu L, Li Z, Shen Q, Xu Q, Li W et al (2019) Design, synthesis and biological evaluation of novel 7-amino-[1,2,4] triazolo [4,3-f] pteridinone and 7-aminotetrazolo [1,5-f] pteridinone derivative as potent antitumor agents. Eur J Med Chem 163:690-709

Jo J, Kim SH, Kim H, Jeong M, Kwak JH, Han YT et al (2019) Discovery and SAR studies of novel 2-anilinopyrimidine-based selective inhibitors against triplenegative breast cancer cell line MDA-MB-468. Bioorg Med Chem Lett 29(1): $62-65$

Kapetanovic IM (2008) Computer-aided drug discovery and development (CADDD): in silico-chemico-biological approach. Chem Biol Interact 171(2): $165-176$

Leelananda SP, Lindert S (2016) Computational methods in drug discovery. Beilstein J Org Chem 12(1):2694-2718

Miller KD, Siegel RL, Lin CC, Mariotto AB, Kramer JL, Rowland JH et al (2016) Cancer treatment and survivorship statistics, 2016. CA Cancer J Clin 66(4): 271-289

Sharma GN, Dave R, Sanadya J, Sharma P, Sharma KK (2010) Various types and management of breast cancer: an overview. J Adv Pharm Technol Res 1(2): 109

\section{Publisher's Note}

Springer Nature remains neutral with regard to jurisdictional claims in published maps and institutional affiliations.

\section{Submit your manuscript to a SpringerOpen ${ }^{\circ}$ journal and benefit from:}

- Convenient online submission

- Rigorous peer review

- Open access: articles freely available online

High visibility within the field

- Retaining the copyright to your article

Submit your next manuscript at $>$ springeropen.com 